\title{
BLAS DE OTERO EN LA REVISTA PAPELES DE SON ARMADANS
}

\author{
Lucía MonTEjo GuRruchaGa \\ UNED. Madrid \\ Imontejo@flog.uned.es
}

\section{RESUMEN}

Blas de Otero mantuvo una larga colaboración con la revista Papeles de Son Armadans. Durante su periodo de vigencia veintitrés años, mostró en ella una veintena de poemas, inéditos en su mayoría. de distintos libros, de distintas etapas de su creación, de caracteristicas fornales $y$ de contenido bien diferenciados. El primero aparecerá en 1950 y los últimos en 1974. El poeta vasco acostumbraba a mostrar poemas inéditos en distintas revistas y antologías con el propósito de sondear el comportamiento censor. A través de Papeles conseguirá eludir el control de la censura que habia prohibido la publicación en libro de muchos de aquellos poemas. Algunos quedarán para siempre entre las páginas de la revista.

Palabras Clave: Blas de Otero; Poesía; inéditos; censura.

\section{ABSTRACT}

Blas de Otero collaborated with the Papeles de Son Armadans magazine for many years. There he showed about twenty poems, most of them unpublished, throughout the twenty three years the magazine lasted. The Basque poet used to display unpublished poems in different magazines and anthologies with the aim of sounding out the censor's reaction. Throughout Papeles he managed to avoid the censorship control which had forbidden publishing most of these poems in a book. 
The first appeared in 1956 and the last ones in 1974. These belong to various books which introduce different topics and formal features. The poems gathered and analyzed in this article were never recovered by the poet and have heen kept on the pages of the magazine.

KEY wORDS: Blas de Otero; poetry; unpublished: censorship.

En abril de 1956 Camilo José Cela crea, a caballo entre Madrid y Palma de Mallorca, la revista mensual de crítica y literatura Papeles de Son Armadans, que durante más de veinte años será una de las más prestigiosas. El que fuera su secretario, José Manuel Caballero Bonald, comenta en sus memorias que la revista jugó, en su primera época, un papel relevante dentro de los avatares y sinsabores de la cultura literaria española, ya que Cela fue muy hábil y tuvo un perspicaz olfato para canalizar a través de la revista, o para no impedir que eso se produjese, todo cuanto estaba ocurriendo en las artes y las letras occidentales y merecía ser tenido en cuenta, con muy específica atención a la literatura nuestra del exilio'. La revista se prolongará hasta 1979.

Blas de Otero va a colaborar pronto en Papeles. Durante más de veinte años irán viendo en ella la luz muchos de sus poemas pertenecientes a distintos libros. Algunos no serán recogidos con posterioridad ni en libros ni en antologías y quedarán olvidados entre sus páginas. Papeles de Son Armadans dedicará un número monográfico al poeta vasco en 1977 en el que participarán los especialistas más destacados².

El poeta vasco acostumbra a mostrar poemas inéditos en distintas revistas y antologías antes de ser recogidos en libro desde el principio de su producción poética, desde los años cuarenta, y mantendrá este hábito hasta su muerte en $1977^{3}$. Esta manera de proceder tiene dos claros propósitos; el primero es conseguir unos pequeños ingresos que le permitan sobrevivir, y el segundo, y no menos importante, sondear el comportamiento censor.

' José Manuel Caballero Bonald, La costumbre de vivir, Madrid, Alfaguara, 2001, 229.

2 Papeles de Son Armadans, XXII, CCLIV-V (mayo-junio 1977). La obra oteriana viene siendo estudiada en las páginas de la revista desde su inicio. El primer artículo dedicado a su obra aparecerá ya en el número 1. En años sucesivos recogerá otros muchos artículos y reseñas. Son: J. M. Caballero Bonald, «Vigencia de la poesía de Blas de Otero", y «Noticia de una crítica ejemplar", PSA, I, I, I (abril 1956), 114-118 y I, III, VIII (noviembre 1956), 221-224 respectivamente. Vicente Aleixandre, «Nuevas figuras (Bousoño, Hierro, Blas de Otero)», XIII (abril 1957). «Los Premios de la Crítica 1958, Ancia de Blas de Otero», IV, XII, XXXVIII (mayo 1959), 223-226. Ricardo Senabre, «Juegos retóricos en la poesía de Blas de Otero», 11, 42, 125 (agosto 1966), 137-150. David Bary, «Sobre el nombrar poético en la poesía española contemporánea», 12, 44, 131 (febrero 1967), 161189. Leopoldo de Luis, «Expresión y reunión (1941-1969), de Blas de Otero», 168 (marzo 1970), 313-317. Andrés Amorós, «Blas de Otero: Historias fingidas y verdaderas», XVI (diciembre 1971), 331-333. M. Luisa Muñiz, «Que trata de España: la trilogía de Blas de Otero», LXI, 198 (septiembre 1972), 99-131. En el monográfico que la revista le dedica en 1977 - CCLIV-V - especialistas -como Emilio Alarcos Llorach, Geoffry R. Barow, Carlos Blanco Aguinaga, Joaquín Galán, Moraina de Semprún, David L. Stixrude-, y poetas -como Vicente Aleixandre, Rafael Alberti, Gabriel Celaya, Jaime Gil de Biedma, José Luis Cano, Ángel González, Jorge Guillén, Claudio Rodríguez, José Ángel Valente, entre otros--, rendirán homenaje al amigo y al poeta.

'Sobre la importancia y alcance de la anticipación de poemas inéditos en revistas y antologías, remito a la introducción a Blas de Otero: Poesía escogida, edición de Sabina de la Cruz y Lucía Montejo, Barcelona, Vicens Vives, 2000 (2." ed. corregida), XLII. Así mismo, a mi artículo, «Blas de Otero en las revistas literarias de los años cincuenta», Boletín de la Fundación Federico García Lorca, 35-36 (2005), 63-83, y a José María Balcells, «Blas de Otero en las antologías poéticas de posguerra», Blas de Otero: Nuevas lecturas críticas (coord., Juan José Lanz, Ínsula 676-677 (abril-mayo 2003), 54-57. 
El primer poema que la revista acogerá, entonces inédito, lleva el título de «Ca ni guer», pertenece a En castellano y fue una elección bien consciente ${ }^{4}$. Es un poema con una larga historia de dificultades que, sin embargo, Papeles imprimirá íntegramente. En el momento de su gestación - 1956- Otero reside en Barcelona, como queda reflejado al pie del poema - Milanesado, 32 - en el entorno del grupo de poetas catalanes en lengua castellana que entonces se está fraguando ${ }^{5}$. Acude a sus tertulias y reuniones acompañado de su amigo José Agustín Goytisolo. Tiene entre manos su libro En castellano, el segundo de la trilogía social, que ha sido considerado su libro más político. En el título ya anuncia el poeta que va a hablar sin ambages sobre los temas que considera acuciantes. Compuesto por poemas arraigados en la circunstancia histórica del momento, es un poemario de gran condensación verbal, un libro formalmente experimental en el que ensaya un nuevo ritmo y emplea técnicas vanguardistas que refuerzan las posibilidades expresivas del lenguaje poético. Con estos ingredientes no parece fácil franquear la censura con la larga historia de encontronazos que ya ha padecido. Sin embargo, conoce el valor del libro y no está dispuesto a renunciar a su publicación ni a publicarlo, de antemano, fuera del país.

Este extraño título - «Ca ni guer»- es un anagrama. Bajo él se escondía el nombre prohibido de la ciudad vasca de Guernica, bombardeada el 26 de abril de 1937 por los aviones alemanes de la Legión Cóndor. El poema estaba dedicado a Picasso -dedicatoria que autocensuró en las primeras ediciones- y era un homenaje al cuadro del mismo nombre encargado por el Gobierno de la República al pintor malagueño en enero de 1937. El poema de Otero reconstruye las visiones surrealistas y las abstracciones figurativas del cuadro mediante técnicas vanguardistas como el desorden que introducen los encabalgamientos, la eliminación de la puntuación ortográfica, la depuración de lo superfluo o la repetición de los símbolos míticos del cuadro —el grito, la ira, el toro, el niño-, lo que suscita en el lector emociones tan violentas como puede experimentar al contemplar el cuadro. Este es el poema:

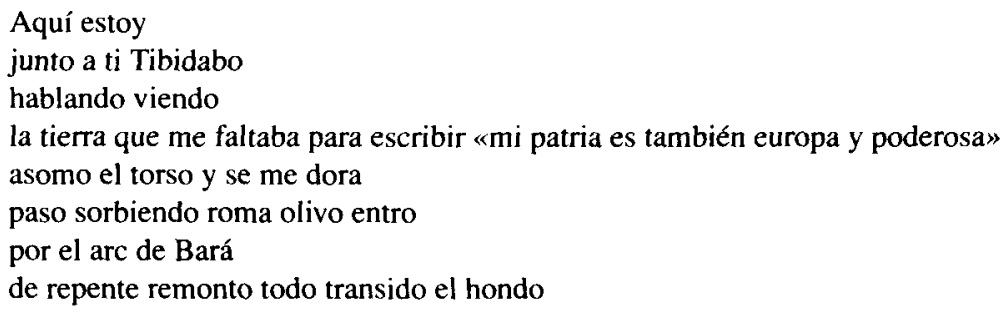

${ }^{4}$ Papeles de Son Armadans, III, IX (diciembre 1956), 295. Será más tarde uno de los que se recojan en Europe (enero-febrero 1958), 117.

`Véase al respecto el artículo de Sabina de la Cruz, «Los poetas del grupo catalán y Blas de Otero», Ínsula, 523-524 (julio-agosto 1990), 17-19.

- Quiero recordar que sus conflictos con el órgano censor vienen de antiguo porque no cesan desde la presentación de su primer libro, Ángel fieramente humano al Premio Adonais en el año 1949. Remito al lector interesado a mis artículos «Blas de Otero y la censura española desde 1949 hasta la transición política. Primera parte: de Ángel fieramente humano a En castellano", RLit, LX, 120 (1998), $491-513$ y Segunda Parte: de Que trata de España a Todos mis sonetos», RLit, LXII, $123(2000)$, 155-175. Algunas revistas tendrán también problemas con el órgano censor por mostrar algunos de sus poemas. Véase al respecto mi artículo «La relación de Blas de Otero con Ínsula. Una colaboración estrecha y continua», Blas de Otero: Nuevas lecturas críticas, op. cit., 58-60. 


\title{
Ebro
}

\author{
a brazazos retorno arribo a ti \\ Vizcaya \\ árbol que llevo y amo desde la raíz \\ y un día fue arruinado desde el cielo. \\ Ved aquí las señales \\ esparcid los vestigios \\ el grito la ira \\ gimiente \\ con el barabay \\ el toro cabreado directamente oíd \\ ira escamio ni dios \\ oh nunca nunca nunca \\ oh quiero quiero que no se traspapelen \\ el cuello bajo la piedra \\ la leche en pleno rostro el dedo \\ de ese niño \\ oh nunca ved aquí \\ la luz equilibrando el árbol \\ de la vida.
}

Este poema y otros de En castellano, que Papeles publicará en números sucesivos, y en los que me detendré a continuación, formaban parte del manuscrito que el poeta presentó a censura en julio de 1958 y le fue devuelto con múltiples tachaduras un mes más tarde y la lacónica sentencia de «Denegado el permiso de publicación». En ese manuscrito «Caniguer» presenta únicamente tres versos tachados ( $\mathrm{y}$ un día fue arruinado bajo el cielo/ ... el toro cabreado directamente oíd/ ...ira escarnio ni dios), lo que da idea de la fina percepción, sensibilidad y agudeza de los censores para detectar los peligros, que para ellos se circunscribían en palabras malsonantes y dioses disminuidos en sus poderes por una minúscula. El título original — «Guernica»-y la dedicatoria los repuso el poeta por primera vez en una edición llevada a cabo fuera de España?

No va a ser este el único poema de En castellano que la revista publique. Unos meses después de la publicación de «Caniguer» aparecerán otros seis poemas inéditos escritos también en Barcelona ${ }^{8}$. Son los titulados «Patria aprendida», «Libertad supone o significa...", "Quiero», "Aire libre», «Pluma que cante», «No salgas, paloma, al campo»".

${ }^{7}$ La primera vez que el poema vio la luz tal y como se había creado fue en su antología Esto no es un libro, Universidad de Río Piedras, Puerto Rico, 1963, 166. No sólo se repone el título, sino también el canto del «Gernikako arbola", símbolo de la patria vasca, que lo encabeza y su traducción castellana, que resultan imprescindibles para entender el poema en su complejidad. Así lo hace notar también Claude Couffon en la primera edición - Parler clair (En castellano), versión francesa de Claude Couffon, París, Pierre Seghers, 1959-en una nota a pie de página: «Le chène de Guernica, symbole des libertés basques». Así aparecerá siempre en las sucesivas ediciones.

* Al pie aparece la dirección de su ocasional domicilio: Vía Layetana, 158.

${ }^{9}$ Papeles de Son Armadans, III, IX, XXVII, (mayo 1958), 329-334. El último, y tomado de Papeles -como se indica al pie--, lo incluye José María Castellet, unos meses más tarde, junto a otros poemas ya publicados en distintos libros y revistas, en Veinte años de poesía española. Antología (1939-1959), Barcelona, Seix Barral, 1960,372 . 
Se publicaron íntegramente - solo uno de ellos presenta variantes-, cuando sin embargo, en el manuscrito salen muy mal parados. En estos poemas se habla de España sin enmascarar el lenguaje y la palabra, que brota conmovida por el dolor de la patria, es sin embargo sometida a un proceso profundo de decantación y sobriedad. Un tono irónico y jocoso suaviza la tragedia sin ocultarla, lo que en ocasiones confiere un aire intrascendente a las realidades más crueles. En uno de ellos, «No salgas, paloma, al campo», arremete abiertamente contra el órgano censor y aunque fue íntegramente tachado en el manuscrito, veía la luz en Papeles con algunas variantes que seguidamente comentaré. Este es el poema.

Sé muchas cosas y otras que me callo.

Cómo decir españa, patria,

libre.

(Espada

libre). Violentas

carcajadas.

Anda

jaleo, jaleo.

No dejan ver lo que escribo,

porque escribo lo que veo.

Sé que Castilla

es ancha.

Cómo decir añil, ayer, molada.

Ayer.

Mañana.

Anda, jaleo,

jaleo.

... lo que veo con los ojos

de la juventud y el pueblo.

El título y los versos en cursiva proceden de la canción tradicional «Anda jaleo, jaleo», recogida y armonizada por Federico García Lorca ${ }^{10}$. A esta canción, muy popular durante la II República, se alude en uno de los colores de su bandera («morada») frente

${ }^{10}$ Es de sobra conocido por todos -no hay estudio que no lo traiga a colación- el arraigo de la obra lorquiana en la lírica tradicional, Cancionero y Romancero y su natural sensibilidad para recoger, percibir, estilizar e inventar a partir de las fuentes tradicionales. El interés y la deuda explícita de Otero con la poesía popular ha sido también objeto de distintos estudios, como lo ha sido la intertextualidad, la inserción en sus textos de palabras procedentes de otros textos. Las frecuentes citas, menciones, referencias y resonancias de estribillos y versos lorquianos que encontramos a lo largo de su obra, sin olvidar el uso intertextual de las canciones populares recogidas y armonizadas por Federico han sido objeto de varios trabajos. Remito al lector interesado a mi tesis doctoral, Teoría poética a través de la obra de Blas de Otero, Madrid, Universidad Complutense, 1986, 551-566 y a los artículos de Ángel González, «La intertextualidad en la obra de Blas de Otero», Al amor de Blas de Otero. edición a cargo de José Ángel Ascunce. Actas de las II Jomadas Internacionales de Literatura: Blas de Otero, Universidad de Deusto, San Sebastián, 1986, 63-75 y de Salvatore J. Poeta, «Recuerdo que en mi infancia: confluencia entre Federico García Lorca y Blas de Otero», Hispanic Journal, Indiana, XI (1990), 77-96. 
al «azul» de los falangistas; en estos últimos tiene su origen el grito («España, una, grande y libre»), sobre el que Otero ironiza en los vv. 2-5. El poema es una burlona diatriba contra la censura, un ataque directo a este órgano represor que le obliga a silenciar la falta de libertad en la España de su tiempo. Formalmente cursa esa denuncia con un verso corto, concentrado, escueto y directo, apoyándose además de en el Cancionero -al que acudirá con frecuencia desde Pido la paz y la palabra-, en expresiones coloquiales, de desenfado en esta ocasión.

Otero se autocensuró al mostrarlo por primera vez en Papeles. Así, figura «Espada» por «España», «añil» por «azul», «molada» por «morada», que repondrá en la versión bilingüe de París y será la definitiva". Bajo el sustantivo «molada» se esconde el color morado de la bandera republicana, símbolo de las libertades perdidas en 1939, que ha dejado paso en el presente de 1957, al azul, color que representa a los falangistas. Estos disfraces, bajo los que en apariencia parecen recomponerse fácilmente las palabras solapadas, se le escapan a un lector no iniciado. Nos encontramos con palabras sencillas que se ven arrastradas por expresiones indirectas, que organizan y modelan el nivel semántico, apto sólo para un lector ideal. En el manuscrito que presentó en censura no quedaron en pie ni la mitad de los versos, mientras que en Papeles salió íntegro con las variantes mencionadas.

Parece ser que Papeles sufría constantes trabas censorias, según afirma Caballero Bonald, pero las amistades que Cela mantenía en las altas jerarquías del Ministerio de Información - del que entonces dependía la Sección de Inspección de Libros- libraron a la revista de todos los ataques y la mantuvieron sin mengua. Quiero recordar que siempre conseguía la autorización, continúa diciendo Caballero Bonald, con lo que Papeles se convirtió en una velada tribuna de desafectos al régimen ${ }^{12}$.

Otero no volverá a las páginas de Papeles de Son Armadans hasta tres años más tarde. En mayo de 1959 tuvieron lugar, organizadas por Camilo José Cela, las Conversaciones Poéticas de Formentor. Eran años difíciles para la organización de eventos que no contaran con el beneplácito del Régimen franquista o surgieran de las instituciones creadas por él. Según parece, al presentar Cela en el Ministerio la lista de los invitados, no se autorizaron los nombres de Dionisio Ridruejo y Jorge Guillén, por lo que algunos otros intelectuales -como Panero, Laín, Aranguren y Rosales- decidieron no participar. A raíz de las Conversaciones se publicó en la Navidad de 1960 un número monográfico de Papeles en el que se recogieron los poemas y textos de los autores que asistieron a los co-

11 El sustantivo «España» puede también ser suplantado por «espuma», tal y como figura en el primer verso de «La va buscando» de En castellano: «Dos espumas frente a frente», en clara alusión a los dos bandos enfrentados en nuestra guerra civil.

12 José Manuel Caballero Bonald, op. cit., 229. La influencia y autoridad de Cela en los medios literarios y extraliterarios eran incuestionables. Había sido nombrado ya académico de la Real Academia de la Lengua en febrero de 1957 con 21 votos y cuatro en blanco y aunque los tiempos no eran propicios ni especialmente buenos para los escritores de la generación de los años cincuenta, él vadeó el temporal con provecho. Manuel L. Abellán, en Censura y creación literaria en España (1939-1976), Barcelona, Península, 1980, 70, afirma que estuvo muy relacionado durante algún tiempo con los servicios de censura, e incluso, ejerció como censor, por lo menos de publicaciones periódicas, y que fue el escritor más tolerado de la época. Sin entrar en detalles nos ha dejado constancia de sus peripecias con la Administración en Historia incompleta de unas páginas zarandeadas. Sin embargo, en todos mis años de investigación en el Archivo General de la Administración, tras el manejo de cientos de expedientes de muy variada procedencia, puedo decir que no he encontrado su firma en ninguno. 
loquios $^{13}$. Lo abría el poema inédito de Blas de Otero «Fechado en Formentor» de En castellano, que llevaba la dedicatoria - A Nicolai Vaptzarov-, porque el poema es un homenaje al poeta búlgaro fusilado en Sofía en el año 1942 por defender la libertad ${ }^{14}$. Es este:

La soledad se abre hambrientamente,

Ah, todo alrededor es hombre y fronda

De hombro arraizado en la raíz más honda:

La tierra, firme, descieladamente.

Ah noche, $y$ noche $y$ noche en pecho $y$ frente,

Tapia del mar, barrido a la redonda

Por ola, y ola y ola en ronda y ronda

Azul y blanca: roja de repente.

Todos los nombres que llevé en las manos

(César, Nazim, Antonio, Vladimiro,

Paul, Gabriel, Pablo, Nicolás, Miguel,

Aragon, Rafael y Mao), humanos

Ángeles, fulgen, suenan como un tiro

Único, abierto en paz sobre el papel ${ }^{15}$.

Sin embargo, y a pesar de las dificultades, Blas de Otero acude a homenajes, conmemoraciones y está presente en los actos poéticos más representativos, además de seguir escribiendo incansablemente nuevos poemas. En marzo de 1959 había participado en París en el homenaje que organizó la universidad de La Sorbona, en representación de los escritores españoles, en conmemoración del XX aniversario de la muerte de Antonio Machado. Aunque en agosto de 1958 se le ha denegado la publicación de En castellano en

1.3 PSA, V, XIX, LVII bis (diciembre 1960). Es un número cuidadosamente ilustrado con el cartel anunciador de Manuel Millares y la colaboración de los pintores Canogar, Viola, Saura, el banón Von Ripper y el propio Cela. El diseño de la portada es de Joan Miró y colaboran los siguientes poetas: Blas de Otero, Gabriel Celaya, Robert Graves, María Villangómez, Alastair Reid, Anthony Kerrigan, Vicente Aleixandre, José Luis Cano, José Agustín Goytisolo, Kaete Moslé, Gerardo Diego, Aquilino Iglesia Alvariño, Camilo José Cela, Joseph Maria Llompart, Rafael Santos Torroella, Blai Bonet, Yves Bonnefoy, Jaime Gil de Biedma, Celso Emilio Ferreiro, León Felipe, Manuel Altolaguirre, Luis Cernuda, Ezra Pound. En este número monográfico no aparecen ni las intervenciones de Dionisio Ridruejo y Guillén, ni las de los intelectuales que rechazaron la invitación como protesta a la restricción gubernamental. Aunque José Luis Cano dice - Los cuadernos de Velintonia, Barcelona, Seix Barral, 1986, 125- que Cela les contó que había conseguido convencer al ministro de que retirara el veto, no parece que la prohibición se levantara. Las Conversaciones tuvieron su continuación en la Colección Formentor que creó Seix Barral. En ella se publicó la más exigente nómina literaria de aquellos años medioseculares y se convirtió en una referencia constante para la vanguardia de la edición europea y en el ágora literaria más importante y famosa de la década de los años sesenta, según afirma Carlos Barral en «La encrucijada de Formentor», Los años sin excusa. Memorias II, Barcelona, Seix Barral, 1978, 239-272.

14 Es sólo un título para la ocasión. Se titulará «La soledad se abre hambrientamente» cuando lo incluya en En castellano. Cambiará de título a «Coral a Nicolai Vaptzarov» cuando lo recoja en la antología Esto no es un libro.

${ }^{15}$ El texto salió íntegro porque el censor desconocía el nombre y significación de la persona objeto de la dedicatoria y no descubrió a los autores que se escondían bajo los nombres de pila (Vallejo, Hikmet, Machado. Maiacovski, Eluard, Celaya, Neruda, Guillén, Hernández, Alberti). Cuando se publique en En castellano presentará algunas modificaciones que se deben, la primera a la corrección de una errata - «arraigado», no «arraizado»- y la segunda al cambio de «ángeles» por «mástiles». Suprime las mayúsculas del inicio del verso. 
España, el poeta no se resigna y no abandona su difusión a través de distintas revistas ${ }^{16}$. Un nuevo poema de En castellano, titulado «Condal entredicha», se publicará pocos meses después en Papeles ${ }^{17}$.

En estos momentos, los poemas del poeta vasco se recogen no sólo en las revistas sino en las antologías más significativas, tanto en las que se publican en España como en el extranjero ${ }^{18}$. Sus libros se reeditan repetidamente, sus poemas se traducen a los más diversos idiomas y la prensa, tanto nacional como extranjera, le dedica la atención que se merece por su calidad estética al tiempo que se hace eco de los avatares que está sufriendo su obra a causa de la censura franquista.

Entre 1960 y 1964 realiza largos viajes —primero a la Unión Soviética y a Chinainvitado por la Sociedad Internacional de Autores, después a Cuba. Buena parte de los poemas que escribe durante estos viajes formarán parte de su libro Que trata de España (1964) con el que cierra el ciclo de tema social, centrándolo en el espacio geográfico de la España de su tiempo. El apartado cuarto reúne algunos de los poemas más bellos sobre el tema de España. Con amorosa delectación toca el paisaje, los nombres de los pueblos, la luz de sus atardeceres, el color de sus piedras, las plazas recónditas. Uno de ellos, «Orozco», entonces inédito, verá la luz en Papeles de Son Armadans ${ }^{19}$. Este poema se concentra en el ámbito del valle de Orozco. Este es, como explica con rigor, Juan José Lanz, el espacio de vinculación con los ancestros, con la tradición, con la memoria y con la intrahistoria, el ámbito de la infancia y de la adolescencia feliz, pero también donde regresar al final de la vida para reintegrarse a las raíces familiares. Orozco es el espacio mitificado de la tradición ruralista vasca, la plasmación de los ideales nostálgicos de una burguesía rural a punto de desaparecer, el espacio de la lengua perdida, de la palabra ancestral usurpada ${ }^{20}$. El poema que aparece en la revista presenta algunas variantes, unas de orden estético, otras de carácter ideológico.

El valle

se tendía al pie del Gorbea,

daba la vuelta alrededor

16 Algunos poemas habían aparecido antes de que se le denegara el permiso, en Poesía española - 25 (1954)—, en Caracola —44 (1956), 52 (1957), 67 (1958)—, en Cuadernos Hispanoamericanos — núms. $91-92$ (1957)—, en Universidad de México —núm. 9 (1958_—, en Ínsula -138-139 (1958)—, y tras ella seguirán apareciendo en Cuadernos de Agora -21-22 (1958)-, en Acento Cultural -4 (1959)-, en el Anejo I (1959) de la Colección Fe de Vida, en Orejudín -6 (1960)-, en Poesía de España -6 (1961)—.

17 Papeles de Son Armadans, VI, XXIII, LXVIII, 228. Llevaba la siguiente dedicatoria: «En el homenaje a la memoria de Carles Riba», que desaparecerá cuando se incluya en el poemario. Quiero recordar que Otero vive cinco años en Barcelona.

18 Pueden verse el estudio de Manuel Mantero, «Quince antologías poéticas (años 60)», Celacanto, Revista de Literatura, Huelva, 3-4, primavera 1991, 76-91 y los dos volúmenes de Emili Bayo, La poesía española en sus antologías (1939-1980), Lérida, Universidad de Lérida, 1994, en los que ofrece una reflexión sobre el fenómeno de las antologías y la lista de poetas más ampliamente representados: Blas de Otero está en el grupo de cabeza.

19 Papeles de Son Armadans, VII, XXV, LXXIII (abril 1962), 63.

20 Juan José Lanz, «La ciudad de memoria: imaginario urbano y lucha de clases en la obra de Blas de Otero", en Nuevas lecturas críticas, op. cit., 23 y 24. Sabina de la Cruz, en la introducción a Blas de Otero, Poemas vascos, Bilbao, Ayuntamiento de Bilbao: Fundación Blas de Otero, 2002, 13, habla del proceso de identificación del poeta con tres espacios privilegiados: Bilbao, Orozco y el mar. Orozco es el más amable, el seno matemo por el que desfila la sombra del niño, la lengua arcaica que oía en los labios de la abuela y se constituye en símbolo de lo amado y lo perdido. 


\author{
de Santa Marina, \\ ascendía \\ hacia Barambio, doblaba \\ hasta la línea del ferrocarril \\ en Llodio, \\ valle delineado por la lluvia \\ incesante, liviana, \\ dando molde, en el lodo, \\ a las lentas ruedas de las carretas \\ tiradas por rojos bueyes, \\ tras la blusa negra o rayada \\ del aldeano con boina, \\ pequeña patria mía, \\ cielo de plata mojada \\ sobre los verdes helechos, \\ la hirsuta zarzamora, \\ el grave roble, los castaños \\ de fruncida sombra, \\ las rápidas laderas de pinares.
}

He aquí el puente

junto a la plaza del Ayuntamiento.

Piedras del río

que mis pies de trece años

traspusieron, frontón

en que tendí, diariamente, los músculos

de muchacho,

tamboril de la aldea

maternal, atardeceres

en las tradicionales romerías

de Ibarra, Murueta,

Luyando, mediodía

en el huerto

de la abuela

luz de agosto irisando los cerezos,

pintando las manzanas, puliendo

el fresco peral,

patria mía pequeña,

escribo desde lejos,

retengo las lágrimas $\mathrm{y}$, por todo

lo que he sufrido y vivido,

soy feliz ${ }^{21}$.

${ }^{21}$ Consideramos variantes de orden estético las siguientes: «cielo de plata», por «cielo de nata», «que mis pies de trece años», por «mis pies treceañeros»; los versos «tamboril de la aldea/ matemal, atardeceres», dejan paso a dos versos de una canción popular vasca, «aires de mis campos/y son del tamboril», que aparecerán en ediciones posteriores. Sin embargo, es de distinto cariz, «escribo desde lejos», que también aparece en la edición de Barcelona. En ediciones posteriores recuperará el verso original, «escribo desde el Kremlin», que no hubiera pasado desapercibido a los ojos del censor. Pablo Jauralde Pou, en el sustancial artículo «La poesía de Blas de Otero», Voz y letra, XIV (2003), 126, analiza el que considera procedimiento relevante en «Orozco», la técnica de la nominación impresionista. 
Este poema desde la primera edición en libro - no aparecieron cuando se publicó en Papeles - iba precedido por dos citas en euskera, la primera de Etxepare (1545) y la segunda del libro Biotz-Begietan (1932) de Lizardi. En los dos textos vascos se exalta la lengua y la personalidad de la tierra vasca. Fue compuesto durante un viaje por la antigua Unión Soviética.

Poco después enviará de nuevo a Papeles otros dos poemas inéditos de Que trata de España, «Juventud imbatida» y «Cantar de amiga $»^{22}$. Ambos están en el manuscrito que Otero remitió a censura, pero el segundo, que aparece con una cruz roja a la izquierda, no fue aprobado y no pudo ser publicado en la primera edición ${ }^{23}$. El poeta lo incluyó entonces en Esto no es un libro. Se trata de una antología que el poeta inicia con estas palabras: «Reúno aquí una serie de poemas, de diversa época, que se refieren a alguna persona o aluden algún nombre. (Incluyo también los prohibidos por la censura en mi nuevo libro publicado este año en Barcelona bajo el título Que trata de España ${ }^{24}$ ). Este libro tuvo que salvar muchos obstáculos interpuestos por la institución censoria y el poeta tuvo que podar y limar muchos poemas. Apuró todos los recursos de ajuste aunque las consecuencias fueron muchas modificaciones significativas, muchos versos suprimidos, poemas mutilados y denegados. La autorización, después de dos años de trámite, se le concede tras pactar muchas modificaciones y después de que le fuera eliminado más de un tercio de los poemas de libro ${ }^{25}$. Este es uno de los poemas denegados que apareció en Papeles sin obstáculos.

\author{
A ti posible compañera \\ camarada \\ diametralmente tendida a mi lado \\ izquierdo bajo el cielo de Castilla \\ a ti \\ pequeño cantar de amigo \\ verso pimpante del Arcipreste \\ estas líneas esta palabra \\ arrancada \\ a la realidad único sueño \\ que amo y veo evidentemente \\ como a ti.
}

Tantos años caminos

aventuras países

papeles enredados en los dedos

fusiles de pie

y siempre siempre

arañándome

españa

\footnotetext{
${ }^{22}$ Papeles de Son Armadans, Año VIII. Tomo XXIX, Núm. LXXXV (abril 1963), 67-69. Al pie se lee la dirección del poeta en Bilbao, Alameda de Recalde, 70.

${ }^{23}$ Blas de Otero, Que trata de España, Barcelona, RM, 1963.

24 Blas de Otero, Esto no es un libro, Río Piedras, Universidad de Puerto Rico, 1963, 97.

25 De inmediato contrata la publicación del libro - esta vez sin recortes- en Francia, aunque parte importante de los poemas censurados aparecen previamente en Esto no es un libro.
} 


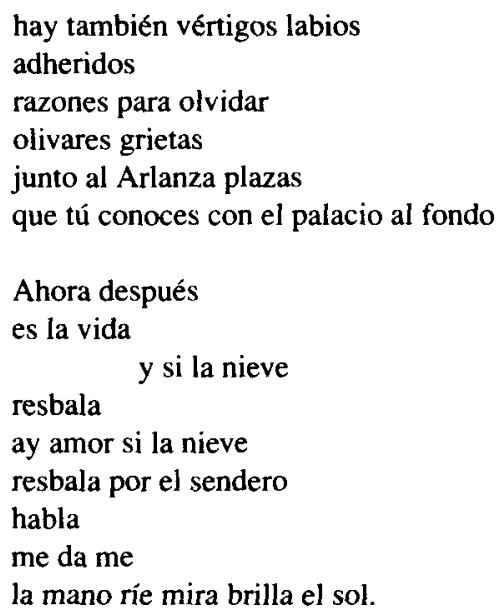

El tema del amor, permanente en la poesía oteriana, aparece revestido de diferentes matices. En una serie de poemas, de la que este forma parte, la ensoñación del sentimiento amoroso acompaña a la descripción llegando a impregnar de erotismo los lugares donde se vivió el episodio amoroso, y la mujer es deseada como "compañera», «camarada», en la expectación de la llegada o en la lucha por la utopía de una sociedad más justa ${ }^{26}$.

Van a pasar más de diez años hasta que Blas de Otero vuelva a Papeles. A principios de 1964 recibe una invitación para viajar a Cuba como jurado del premio de poesía "Casa de las Américas» y en la isla permanecerá hasta abril de 1968. En 1966, durante su estancia en La Habana, comienza a escribir las prosas de Historias fingidas y verdaderas, que quedan terminadas en 1968, en el momento de su vuelta a España. Aunque llega a Madrid gravemente enfermo, comienza a escribir a un ritmo acelerado. Durante diez años seguirá llenando carpetas que llamó en un principio Hojas de Madrid y que fueron más tarde ampliándose con La galerna. En 1969 incluyó algunos de esos poemas en la antología Expresión y reunión; con veinticinco más formó el libro Mientras (1970), y en años sucesivos distribuyó algunos más en otras antologías (País, Verso y prosa, Poesía con nombres) y en varias revistas, entre ellas Papeles de Son Armadans, que en marzo de 1974 incluirá la separata "Escrito para», un grupo de nueve poemas, ocho de ellos inéditos ${ }^{27}$. Llevan al pie la fecha de composición, entre 1969 y 1974, y están dedicados a amigos creadores, poetas y pintores. Con posterioridad, algunos pasarán a distintas antologías, pero otros quedarán entre las páginas de la revista. Uno, «Materia», había aparecido ya en Mientras; otros cuatro, «Palabra en piedra», «Historia de una palabra», «Ante la pared el lienzo el aire» y «José Menese», formarán parte en 1977 de Poesía con nombres ${ }^{28}$. Otro, «Lo indeleble», será recogido en 1995 y $2002^{29}$. Los tres

\footnotetext{
${ }^{26}$ Un estudio detenido sobre este tema se encuentra en la introducción a Blas de Otero, Poesía escogida, ed. de Sabina de la Cruz y Lucía Montejo, op. cit., XXXVIII-XLI.

${ }^{27}$ Papeles de Son Armadans, 216 (marzo 1974), 252-264.

28 Blas de Otero, Poesía con nombres, Madrid, Alianza Editorial, 1977.

29 Blas de Otero, Poesía escogida, op. cit., 190 y Antología poética, Bilbao, Colección Deia Bilduma, 2002, 232.
} 
restantes, «Trozos de patria», «Danzas», y «León Felipe», no figuran en ningún otro lugar. El primero, «Trozos de patria», lleva la siguiente dedicatoria: «Ceballos, muerto en el destierro».

Era el atardecer y caminábamos por una calle grisácea de París.

El viento arrastraba hojas de periódico, caras de niño, nada.

Callábamos. Nuestros pasos sonaban inseguramente, entonces tú dijiste: «A nuestra espalda, España perdida hace mil años...»

Entramos en un café donde unos hombres sin rostro hablaban con las manos llenas de sangre.

Bebimos en silencio. La noche se adentraba en los cristales, lienzos esbozados en tu estudio del pasadizo con plantas asombradas.

Salimos, y en la esquina te abracé por última vez como quien pierde un trozo de patria, una vocación tenaz, un amigo.

El recuerdo del amigo, incorruptible en su propósito de lucha y esperanza, inspira este homenaje. Debemos recordar que el poeta sale de España por primera vez en 1952 y pasa en París casi un año. Allí entra en contacto con los exiliados españoles comunistas y, a través de las lecturas y las conversaciones, asume la interpretación marxista de la historia, que será crucial para su vida y para su obra.

El segundo de los poemas olvidados en este número de la revista, «Danzas», compuesto en junio de 1973, está dedicado a la bailarina Rosario Escudero ${ }^{30}$.

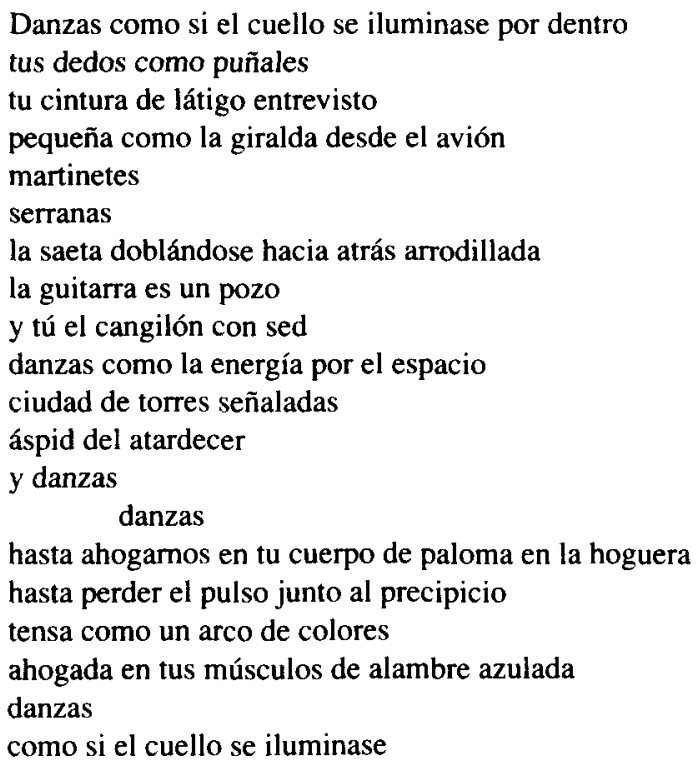

ardiera

${ }^{30}$ José Manuel Caballero Bonald, en una entrevista aparecida en Ancia, Bilbao, Fundación Blas de Otero, 3 (2004), hace referencia a esta bailarina y a una foto en la que aparecen ambos poetas junto a Gabriel Celaya en casa de ella. 
Esta viva y pormenorizada descripción de una bailarina en el momento de su actuación aparece cargada de connotaciones simbólicas. Aunque los poemas de su último periodo creativo son de diversa factura, predomina en ellos el verso libre, y puede mezclar en un mismo poema versos de medida muy dispar, desde el versículo al verso de una sola sílaba, con esquemas que se basan, en muchos casos, en el principio de repetición o recurrencia vinculados con frecuencia a las repeticiones anafóricas, y sin desechar el realismo, como en este, un clima surrealista envuelve las composiciones, con asociaciones ilógicas y escapadas al absurdo. Basará su ritmo en las simetrías y paralelismos conceptuales, en las recurrencias de palabras. Somete sus poemas a un proceso de rigor verbal y depuración formal poniendo especial atención en los múltiples valores sensoriales del lenguaje. Curiosamente no es la primera vez que dedica un poema a una bailarina. Ya le había dedicado varios a La Chunga, la gitana de los pies descalzos ${ }^{31}$.

El tercero de los poemas olvidados en Papeles es el titulado «León Felipe». Fue escrito en febrero de 1974 en homenaje a una de las figuras decisivas de la lírica española del exilio. Al tiempo que intercala y recrea algunos de sus más conocidos versos, Otero evoca la lucha del poeta, la nostalgia de las tierras españolas que vertiera con tono profético y combativo en su poemario Español del éxodo y del llanto (1939).

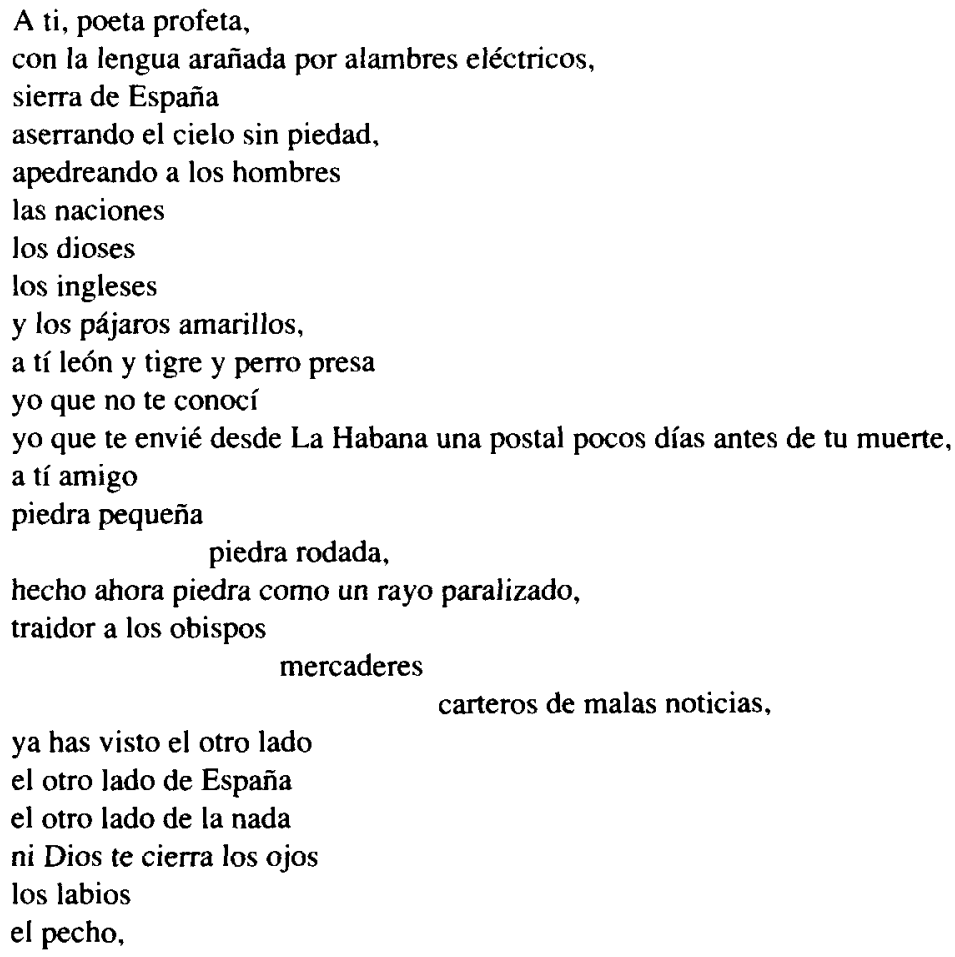

"El poeta conoció a La Chunga en Barcelona y le dedicó varios poemas no recogidos en libro ni en antologías. Se puede ver al respecto mi artículo «Blas de Otero en las revistas literarias de los años cincuenta», Boletín de la Fundación Federico García Lorca, 35-36 (2005), 63-83. 
yo pecador de mi patria

yo arrendatario de mi patria

yo vagamundo con las ropas deshilachadas

te canto desde abajo

te olvido para nunca

aquí en México

aquí en América

aquí en mi desesperación habilidosa,

agur agur

dentro de poco nos veremos.

Todavía, y antes de su muerte, que llegará el veintinueve de junio de 1979, algunos meses después de cumplir sesenta y tres años, Blas de Otero recibirá en 1977 el homenaje de Papeles con un número monográfico.

La colaboración del poeta con la revista ha durado más de veinte años, casi todo el tiempo que esta mantuvo su vigencia. Ha mostrado en ella una veintena larga de poemas -inéditos en su mayoría-, de distintos libros, de distintas etapas de su creación, de características formales y de contenido bien diferenciados. Además, a través de Papeles ha podido eludir el control de la censura que había prohibido la publicación en libro de muchos de aquellos poemas.

\section{OBRAS CITADAS}

AA.VV., Blas de Otero: Nuevas lecturas críticas. (coord., Juan José Lanz), Ínsula, 676-677 (abrilmayo 2003).

ABELLÁN, Manuel L., Censura y creación literaria en España (1939-1976), Barcelona, Península, 1980. Barral, Carlos, Los años sin excusa. Memorias II, Barcelona, Seix Barral, 1978.

Balcells, José María, "Blas de Otero en las antologías poéticas de posguerra», Blas de Otero: Nuevas lecturas críticas, op. cit., 54-57.

Caballero Bonald, Manuel, La costumbre de vivir, Madrid, Alfaguara, 2001.

Cano, José Luis, Los cuadernos de Velintonia, Barcelona, Seix Barral, 1986.

Castellet, José María, Veinte años de poesía española. Antología (1939-1959), Barcelona, Seix Barral, 1960.

CRUZ, Sabina de la, «Los poetas del grupo catalán y Blas de Otero», Ínsula, 523-524 (julio-agosto 1990), 17-19.

GONZÁLEZ, Ángel, «La intertextualidad en la obra de Blas de Otero», Al amor de Blas de Otero, edición a cargo de José Ángel Ascunce. Actas de las II Jornadas Internacionales de Literatura: Blas de Otero, Universidad de Deusto, San Sebastián, 1986, 63-75.

Jauralde Pou, Pablo, «La poesía de Blas de Otero», Voz y letra, XIV/1 (2003), 95-150.

LANZ, Juan José, «La ciudad de memoria: imaginario urbano y lucha de clases en la obra de Blas de Otero", Nuevas lecturas críticas, op. cit., 23 y 24.

Montejo Gurruchaga, Lucía, Teoría poética a través de la obra de Blas de Otero, Madrid, Universidad Complutense, 1986.

- «Blas de Otero y la censura española desde 1949 hasta la transición política. Primera parte: de Ángel fieramente humano a En castellano, RLit, LX, 120 (1998), 491-513.

- «Blas de Otero y la censura española desde 1949 hasta la transición política. Segunda parte: de Que trata de España a Todos mis sonetos», RLit, LXII, 123 (2000), 155-175. 
-, «La relación de Blas de Otero con Ínsula. Una colaboración estrecha y continua», Blas de Otero: Nuevas lecturas críticas. (Coord., Juan José Lanz), Ínsula, 676-677 (abril-mayo 2003), 5860 .

-, «Blas de Otero en las revistas literarias de los años cincuenta», Boletín de la Fundación Federico García Lorca, 35-36 (2005), 63-83.

OTERo, Blas de, Parler clair, (En castellano) ed. bilingüe, traducido y prologado por Claude Couffon, Pierre Seghers, París, 1959.

- Que trata de España, Barcelona, RM, 1963.

-, Esto no es un libro, Río Piedras, Universidad de Puerto Rico, 1963.

_, Poesía escogida, ed. de Sabina de la Cruz y Lucía Montejo, Barcelona, Vicens Vives, 2000 (2. ${ }^{\text {a }}$ ed. corregida).

- Poemas vascos, Bilbao, Ayuntamiento de Bilbao: Fundación Blas de Otero, 2002.

- Antología poética, Bilbao, Colección Deia Bilduma, 2002.

POETA, Salvatore J., «Recuerdo que en mi infancia: confluencia entre Federico García Lorca y Blas de Otero», Hispanic Journal, XI (1990), 77-96. 